\title{
Prevalence of weak D phenotype among D negative C/E+ blood donors in Morocco
}

\author{
Mariam EL Wafi, Houria EL Housse, Nadia Nourichafi, \\ Kamal Bouisk, Mohamed Benajiba, Norddine Habti
}

\begin{abstract}
Aims: Determination of $D$ variants is important for selection of blood products and to prevent anti-D-related hemolytic disease of the fetus and newborn. The prevalence of weak $D$ phenotypes varies significantly among different ethnic populations. In Morocco, D variants have not been fully characterized. The purpose of this study was to determine prevalence of weak $D$ among $D$ negative and $C / E+$ blood donors and distribution of Rhesus blood group antigens using serologic methods. Methods: A total of 15,865 blood samples from Moroccan blood donors were tested for $\mathrm{D}, \mathrm{C}, \mathrm{c}, \mathrm{E}$, e antigens by routine serologic methods. Among blood donors serologically $D$ negative $C+$ and/or $E+, 63$ samples were tested for weak $D$ by indirect antiglobuline test, enzymatic treated cells test and adsorption elution technique. Results: Among 63 samples tested, 10 were positive by serologic methods
\end{abstract}

Mariam EL Wafi', Houria EL Housse ${ }^{1}$, Nadia Nourichafi ${ }^{2}$, Kamal Bouisk ${ }^{2}$, Mohamed Benajiba ${ }^{3}$, Norddine Habti ${ }^{1,3,4}$

Affiliations: ${ }^{1}$ Laboratory of Biotechnology and Experimental Medicine - Faculty of Medicine and Pharmacy Casablanca Hassan II University of Casablanca; ${ }^{2}$ Regional Blood Transfusion Center in Casablanca; ${ }^{3}$ National Blood Transfusion and Hematology Center; ${ }^{4}$ Laboratory of Hematology, Cellular and Genetic Engineering - Faculty of Medicine and Pharmacy Casablanca - Hassan II University of Casablanca, Morocco.

Corresponding Author: M. EL Wafi, Laboratory of Biotechnology and Experimental Medicine, Faculty of Medicine and Pharmacy, University Hassan II, 19 Rue Tarik Ibnou Ziad, B.P. 9154, Casablanca, 20000, Morocco; Email: mariam. benabdeljalil@gmail.com

Received: 4 August 2015

Accepted: 4 November 2015

Published: 24 February 2016
(15.87\%). Six samples identified as weak $D$ by enzymatic test and four samples identified as Del by adsorption elution. Rhesus blood group antigens are distributed as DCcee: $38.85 \%$ and dccee : $8.77 \%$. Conclusion: The prevalence of $D$ variants must be considered in transfusional and obstetrical strategy for RhD typing to ensure blood transfusion safety by optimizing the management of $D$-negative $R B C$ units and $R h$ immune globulins.

Keywords: Anti-D immunization, D variant, Moroccan population, $\mathrm{RhD}, \mathrm{RBC}$ serology, Transfusion, Weak D phenotype

\section{How to cite this article}

EL Wafi M, EL Housse L, Nourichafi N, Bouisk K, Benajiba M, Habti N. Prevalence of weak D phenotype among $\mathrm{D}$ negative $\mathrm{C} / \mathrm{E}+$ blood donors in Morocco. Int J Blood Transfus Immunohematol 2016;6:3-7.

Article ID: 100022IJBTIMW2016

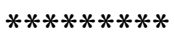

doi:10.5348/ijbti-2016-22-OA-2

\section{INTRODUCTION}

The $\mathrm{Rh}$ blood group system is one of the most polymorphic systems in human. It is involved in the incompatible $\mathrm{RBC}$ transfusions conflicts and in the hemolytic disease of the newborn due to the maternalfetal blood group incompatibility [1].

By year 2015, $58 \mathrm{Rh}$ antigens have been identified. The most common and immunogenic are D, C, E, c, 
and e [2]. The D antigen is encoded by the RHD gene while RhC, RhE, Rhc and RHe antigens are encoded by the RHCE gene [3, 4]. The RHD gene polymorphism leads to phenotypic polymorphism $\mathrm{D}$ variants including weak D, Del and partial D. The weak D phenotype corresponds to a decrease in the expression of $\mathrm{D}$ antigen [5]. The weakest RhD (Del) is detected by adsorption-elution test [6]. Partial D phenotype corresponds to qualitative changes in $\mathrm{D}$ antigen consistent with the absence of some epitopes [7].

More than 100 variant of $\mathrm{D}$ types have been reported in literature. The prevalence of $\mathrm{D}$ variants varies among populations. Between 0.2 to $1 \%$ of Caucasians carry $\mathrm{D}$ variant, while almost $30 \%$ of $\mathrm{D}$ negative Asians are phenotyped Del $[8,9]$. There are few studies of RHD alleles among African populations. Wagner et al. reported a frequency of $31 \%$ of aberrant RHD allele among Africans of Mali while Kabiri et al. reported $0.4 \%$ in Morocco [10,11]. However, D variants are more frequent among subjects D negative RhC and/or RhE positive [12].

In transfusion medicine, the determination of these D variants is important to ensureblood safety. Their presence causes difficulties in hematology and blood transfusion laboratories. Related discrepancies observed depend on the anti-D reagents and/or serological techniques used. Some weak D and partial D are not detected by serology techniques. Transfused D negative patients with RBCs carrying these variants may develop alloantibodies against the $D$ antigen [13, 14]. Immunohematological sensitive tests such as enzyme test, indirect antiglobuline test and adsorption-elution technique are necessary to detect some weak D.

Considering the above technical difficulties and the importance of the Rhesus system in transfusion medicine and hemolytic disease of the newborn, it is necessary to determine population frequencies of $\mathrm{D}$ variants. We aimed to determine the prevalence of weak $\mathrm{D}$ variants in Moroccan blood donors phenotyped $\mathrm{D}$ negative $\mathrm{RhC}$ and/or RhE positive.

\section{MATERIALS AND METHODS}

\section{Rhesus phenotypes}

From November 2011 to June 2012, blood samples were collected at the Regional Blood Transfusion Center in Casablanca (CRTSC) from 15,865 blood donors. Rhesus typing (D, C, E, c, e) is performed using automated analyzer (Olympus PK 7300, Japan) on red cells treated and suspended in $0.9 \%$ bromelain-PBS solution $(1 \mathrm{~g} / \mu \mathrm{l})$ and incubated at $37^{\circ} \mathrm{C}$ for 60 minutes. The tests were performed with monoclonal antibodies: anti-D (clones $\mathrm{n}^{\circ}: \mathrm{P}_{3} \times 61+\mathrm{P}_{3} \times 21223 \mathrm{~B} 10+\mathrm{P}_{3} \times 290+\mathrm{P}_{3} \times 35$, Diagast, France), anti-C (clones $n^{\circ}: 25513 \mathrm{G} 8 * \mathrm{P}_{3}+$ MS24, Diagast, France), anti-c (clone $n^{\circ}: 951$, Diagast, France), anti-E (clone ${ }^{\circ} 906$, Diagast, France), and anti-e (clone $n^{\circ}: \mathrm{P}_{3}$ GD512+MS63, Diagast, France).

\section{Weak D Testing}

Among blood donors phenotyped D negative, $\mathrm{RhC}$ and/or RhE positive, 63 samples randomly selected were tested by indirect antiglobuline test and papain test using the manufacturer's recommendations. The antibodies used were: anti-D (IgM/IgG blend, BGDooo10, Fortress Diagnostics, UK) and an anti-IgG antiglobulin + polyspecific anti-C3d (clones $\mathrm{n}^{\circ} 18833+18896+$ 12011D10, Diagast, France). Results were read by two observers independently. Samples typed as D negative by indirect antiglobuline test and enzymatic test, were tested for the Del phenotype by adsorption elution. RBCs washed 3 times with an isotonic solution of $\mathrm{NaCl}$ at $0.9 \%$ were incubated with anti-D (v/v) for $45 \mathrm{~min}$ at $37^{\circ} \mathrm{C}$. After centrifugation and washing the pellet 6 times, RBCs were re-suspended in an isotonic solution (2v/v) and incubated at $56^{\circ} \mathrm{C}$ for $15 \mathrm{~min}$. After a second centrifugation (400 $\mathrm{g} / 5 \mathrm{~min}$ ), the supernatant was incubated separately with $5 \%$ RBCs positive (D+) and negative (D-) suspensions controls. RBCs controls (D+ and D-) were provided by National Quality Control Laboratory of Morocco. After incubation at $37^{\circ} \mathrm{C}$ for $45 \mathrm{~min}$, results were interpreted with the naked eye and microscopically by two observers.

\section{RESULTS}

\section{Rhesus phenotype frequencies}

A percentage of $9.5 \%(1519 / 15865)$ of samples were phenotyped D negative. Among them, 8.3\% (127) were $\mathrm{RhC}$ and/or RhE positive. The DCcee was the most common phenotype. Table 1 gives the percentages of different Rhesus phenotypes.

\section{Weak D phenotype frequency among RhD negative RhC and/or RhE positive individuals}

$63 \mathrm{D}$ negative blood donors randomly selected are tested: 28 were $\mathrm{RhC}$ positive, 26 were RhE positive, and 9 were RhCE positive. Immunohematological sensitive tests revealed 10 weak D positive among $63(15.87 \%)$ as given in Table 2.

\section{DISCUSSION}

This study revealed $15.87 \%$ of weak D among subjects C and/orEpositiveandpreviouslydocumentedas Dnegative. This percentage depends on immunohematological techniques, and reagents used (anti-RH1, antiglobulin, papain, bromelain) $[15,16]$. The omission of weak $\mathrm{D}$ variants by immunohematological techniques has been reported by several authors in several countries [17-19]. D variants are found among $\mathrm{D}$ negative $\mathrm{C}$ and/or $\mathrm{E}$ positive blood donors [12]. It is recommended in Australia to use indirect antiglobuline test among $\mathrm{C}$ and/or $\mathrm{E}$ positive 
donors to reduce alloimmunization, cost and time testing [19]. In Morocco, indirect antiglobuline test are not used to detect weak D. For transfusion safety, the donors phenotyped $\mathrm{D}$ negative $\mathrm{RhC}$ and/or RhE positive are classified as $\mathrm{D}$ positive donors, and $\mathrm{D}$ negative recipients in the blood transfusion center in Morocco, despite the lack of data on D variants. However, in Egyptian study, Eiman Hussein et al. suggested that D variants are more likely found in blood donors phenotyped Rhce [20].

In our study, the serological methodology has not distinguished between weak D and partial-weak D. The later represents $5-10 \%$ of weak D detected by serology $[15,21,22]$. Transfusion of partial-weak D recipients with $\mathrm{D}$ positive RBCs may induce alloimmunization against the missing epitopes. A typical example of these variants is DVI which may cause hemolytic disease of the newborn [23]. To prevent alloimmunization, the FDA recommends to use monoclonal anti-D which does not recognize DVI variant among recipients and pregnant women [24]. The alternative solution would be the RH genotyping [15].
Table 1: Rh phenotypes frequencies in Moroccan blood donors

\begin{tabular}{lcl} 
Phenotypes & Number of blood donors & $\%$ \\
\hline DCcee & 6163 & $38.85 \%$ \\
Dccee & 3119 & $19.66 \%$ \\
DCCee & 2523 & $15.9 \%$ \\
DccEe & 1187 & $7.48 \%$ \\
DCcEe & 1162 & $7.32 \%$ \\
DccEE & 166 & $1.05 \%$ \\
DCCEe & 26 & $0.16 \%$ \\
dccee & 1392 & $8.77 \%$ \\
dCcee & 96 & $0.6 \%$ \\
dccEe & 28 & $0.18 \%$ \\
dCcEe & 2 & $0.012 \%$ \\
dccEE & 1 & $0.006 \%$ \\
\hline
\end{tabular}

Table 2: Serologic profile of weak D phenotypes

\begin{tabular}{lllllllllll} 
Samples & $\mathbf{1}$ & $\mathbf{2}$ & $\mathbf{3}$ & $\mathbf{4}$ & $\mathbf{5}$ & $\mathbf{6}$ & 7 & $\mathbf{8}$ & 9 & 10 \\
Phenotypes & Ccee & Ccee & ccEe & CcEe & ccEe & ccEe & CcEe & CcEe & Ccee & Ccee \\
IAT & - & - & - & - & - & - & - & - & - & - \\
Enzyme test & + & + & + & + & - & - & - & - & + & + \\
Adsorption-elution & NT & NT & NT & NT & + & + & + & + & - & - \\
\hline
\end{tabular}

+: Positive agglutination, -: No agglutination, NT: Not tested

RhD phenotyping showed 9.5\% D negative blood donors in Casablanca. This percentage is consistent with previous studies [25]. The frequency of $\mathrm{RhD}$ negative varies between populations: $15 \%$ in Caucasians, $3-7 \%$ in Africans, 7-8\% among Black Americans, and $<1 \%$ in Asians [26-28]. Comparing different rhesus phenotypic frequencies, one can observe similarity between populations of Morocco, (DCcee: $38.85 \%$ dccee: 8.77 \%), Maghreb (DCcee: 37.55\% dccee: 6.12\%) and Arab Gulf (DCcee: $30.9 \%$ dccee: $7.3 \%$ ) [29-31]. These results confirm previous studies concerning ABO system. Intermediate values between black Africans and Caucasians are explained by the history of migrations of different peoples in the Maghreb [32].

\section{CONCLUSION}

Immunohematological sensitive test revealed that $\mathbf{1 5 . 8 7 \%}$ of blood donors $\mathrm{RhD}$ negative, $\mathrm{RhC}$ and/or $\mathrm{RhE}$ positive, previously documented as $\mathrm{RhD}$ negative were weak D. Our results suggest that it would be important for Blood Centers to continuously develop new strategies for $\mathrm{Rh}$ phenotyping. This will avoid unnecessary injections of immunoglobulins RhIG for weak D pregnant women and transfusion of D negative patients with weak D RBCs, and therefore ensure better management of $\mathrm{D}$ negative blood stock. Since immunohematological techniques remain insufficient, RHD genotyping is recommended to identify RHD variants.

\section{$* * * * * * * * *$}

\section{Author Contributions}

Mariam EL Wafi - Substantial contributions to conception and design, Acquisition of data, Analysis and interpretation of data, Drafting the article, Revising it critically for important intellectual content, Final approval of the version to be published

Houria EL Housse - Substantial contributions to conception and design, Acquisition of data, Analysis and interpretation of data, Drafting the article, Revising it critically for important intellectual content, Final approval of the version to be published

Nadia Nourichafi - Substantial contributions to conception and design, Acquisition of data, Analysis and interpretation of data, Drafting the article, Revising it critically for important intellectual content, Final approval of the version to be published 
Kamal Bouisk - Substantial contributions to conception and design, Acquisition of data, Analysis and interpretation of data, Drafting the article, Revising it critically for important intellectual content, Final approval of the version to be published

Mohamed Benajiba - Substantial contributions to conception and design, Acquisition of data, Analysis and interpretation of data, Drafting the article, Revising it critically for important intellectual content, Final approval of the version to be published

Norddine Habti - Substantial contributions to conception and design, Acquisition of data, Analysis and interpretation of data, Drafting the article, Revising it critically for important intellectual content, Final approval of the version to be published.

\section{Guarantor}

The corresponding author is the guarantor of submission.

\section{Conflict of Interest}

Authors declare no conflict of interest.

\section{Copyright}

(C) 2016 Mariam EL Wafi et al. This article is distributed under the terms of Creative Commons Attribution License which permits unrestricted use, distribution and reproduction in any medium provided the original author(s) and original publisher are properly credited. Please see the copyright policy on the journal website for more information.

\section{REFERENCES}

1. Mollison PL, Engelfriet CP, Conteras M. The Rh blood group system. In: Blood Transfusion in Clinical Medicine. 9ed. Oxford. Blackwell Scientific Publication 1993. p. 2008-9.

2. Flegel WA. The genetics of the Rhesus blood group system. Blood Transfus 2007 Apr;5(2):50-7.

3. Avent ND, Ridgwell K, Tanner MJ, Anstee DJ. cDNA cloning of a $30 \mathrm{kDa}$ erythrocyte membrane protein associated with $\mathrm{Rh}$ (Rhesus)-blood-group-antigen expression. Biochem J 1990 Nov 1;271(3):821-5.

4. Le van Kim C, Mouro I, Chérif-Zahar B, et al. Molecular cloning and primary structure of the human blood group RhD polypeptide. Proc Natl Acad Sci U S A 1992 Nov 15;89(22):10925-9.

5. Wagner FF, Frohmajer A, Ladewig B, et al. Weak D alleles express distinct phenotypes. Blood $2000 \mathrm{Apr}$ 15;95(8):2699-708.

6. Okubo Y, Yamaguchi H, Tomita T, Nagao N. A D variant, Del? Transfusion 1984 Nov-Dec;24(6):542.

7. Flegel WA, Wagner FF. RHD epitope density profiles of RHD variant red cells analyzed by flow cytometry. Transfus Clin Biol 1996;3(6):429-31.

8. Flegel WA, Wagner FF. Molecular biology of partial D and weak D: implications for blood bank practice. Clin Lab 2002;48(1-2):53-9.
9. Sun CF, Chou CS, Lai NC, Wang WT. RHD gene polymorphisms among RhD-negative Chinese in Taiwan. Vox Sang 1998;75(1):52-7.

10. Wagner FF, Moulds JM, Tounkara A, Kouriba B, Flegel WA. RHD allele distribution in Africans of Mali. BMC Genet 2003 Sep 24;4:14.

11. Kabiri Z, Benajibaa M, Hajjout K, Dakka N, Bellaoui $\mathrm{H}$. Prévalence du phénotype $\mathrm{Rh} \mathrm{D}$ faible chez les donneurs de sang Rh D négatif au Maroc. Immunoanalyse \& Biologie Spécialisée 2013;28(1):36.

12. Gassner C, Doescher A, Drnovsek TD, et al. Presence of RHD in serologically D-, C/E+ individuals: a European multicenter study. Transfusion 2005 Apr;45(4):527-38.

13. Wagner T, Körmöczi GF, Buchta C, et al. Anti-D immunization by DEL red blood cells. Transfusion 2005 Apr;45(4):520-6.

14. Mota M, Fonseca NL, Rodrigues A, Kutner JM, Castilho L. Anti-D alloimmunization by weak D type 1 red blood cells with a very low antigen density. Vox Sang 2005 Feb;88(2):130-5.

15. Denomme GA, Dake LR, Vilensky D, Ramyar L, Judd WJ. Rh discrepancies caused by variable reactivity of partial and weak D types with different serologic techniques. Transfusion 2008 Mar;48(3):473-8.

16. Williams M. Monoclonal reagents for rhesus-D typing of Irish patients and donors: a review. Br J Biomed Sci 2000;57(2):142-9.

17. Opoku-Okrah C, Amidu N, Amoah-Sakyi S. Detection of weak D (Du) phenotype among Rh-D negative males and females in Kumasi, Ghana. Journal of Science \& Technology (Ghana) 2008;28:34-40.

18. Hussein E, Teruya J. Weak D types in the Egyptian population. Am J Clin Pathol 2013 Jun;139(6):80611.

19. Engelfriet CP, Reesink HW. Testing for weak D. Vox Sanguinis 2006;90:140-53.

20. Hussein E, Teruya J. Serologic findings of RhD alleles in Egyptians and their clinical implications. Transfus Apher Sci 2014 Oct;51(2):184-7.

21. Rupreht RR, Pretnar Hartman K, Galvani V, Rozman $\mathrm{P}$, Curin Serbec V. Weak D and partial D in Slovenian population through serology and genotyping. Pflugers Arch 2000;440(5 Suppl):R195-6.

22. Christiansen M, Samuelsen B, Christiansen L, Morbjerg T, Bredahl C, Grunnet N. Correlation between serology and genetics of weak $\mathrm{D}$ types in Denmark. Transfusion 2008 Jan;48(1):187-93.

23. Lacey PA, Caskey CR, Werner DJ, Moulds JJ. Fatal hemolytic disease of a newborn due to anti-D in an Rh-positive Du variant mother. Transfusion 1983 Mar-Apr;23(2):91-4.

24. Judd WJ, Moulds M, Schlanser G. Reactivity of FDAapproved anti-D reagents with partial D red blood cells. Immunohematology 2005;21(4):146-8.

25. Sbiti M, Bahji M, Zahid H, Rafi M, Benkirane M. Les fréquences phénotypiques et génotypiques des systèmes $\mathrm{ABO}$, Rh et Kell dans la population Marocaine. La Gazette de la Tansfusion 2002;175.

26. Westhoff CM. The structure and function of the Rh antigen complex. Semin Hematol 2007 Jan;44(1):4250.

27. Reid ME, Lomas-Francis C. The Blood Group Antigen Facts Book. 2ed. New York: Elsevier Academic Press; 2004. 
28. Daniels G. Human blood groups. Oxford: Blackwell Science Ltd.; 2002. p. 257-355.

29. Benahadi A, Boulahdid S, Adouani B, et al. Mapping rare erythrocyte phenotypes in morocco: a tool to overcome transfusion challenges. J Blood Transfus 2014;2014:707152.

30. Kacem N, Chakroun T, Moussa H, et al. RHD zygosity assignments based on most probable genotype and hybrid Rhesus box detection in Tunisia. Transfus Med 2012 Oct;22(5):362-6.
31. Jenan Y Taha. Rh antigen and phenotype frequency in kalba region, UAE. Bahrain Medical Bulletin 2012;34:1-5.

32. Habti $\mathrm{N}$, Nourichafi $\mathrm{N}$, Benchemsi N. ABO polymorphism in blood donors in Morocco.

[Article in French]. Transfus Clin Biol 2004 Apr;11(2):95-7.
Access full text article on other devices

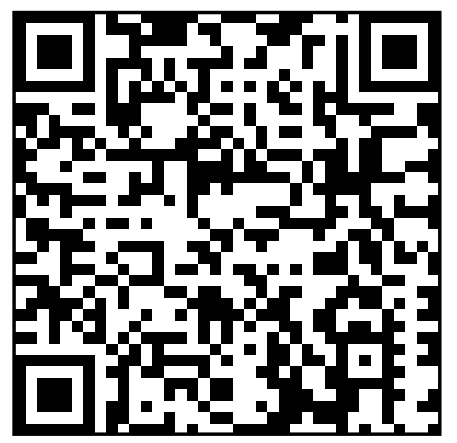

Access PDF of article on other devices



